\title{
GEOGRAFIESE NAAMGEWING EN GODSDIENSTIGE
}

AGTERGROND.

Dit is van al die ou Semitiese volkere waar dat die volk se godsdienstige oortuiginge in sy naamgewing tot uiting kom, omdat elke naam by hulle 'n betekenis gehad, en hul gedagte of begeertes aangaande die voorwerp wat die naam dra, openbaar het. By hulle was

17) E. Sellin, Das Zwölfprophetenbuch. Kommentar zum Alten Testament, Band XII. I. Leipzig, A. Deichert. 1929, p. 100. 
'n naam nie net ' $\mathrm{n}$ middel om ' $\mathrm{n}$ persoon of ding van andere te onderskei nie, maar was 'n uitdrukking van die wese van die voorwerp. the packet, so to say; and importance is attached to the knowledge of a name (Gen. 32:39; Judges $13: 18$ ), and to the change of a name (Gen. $35: 10$ ), for the name is as it were, an integral part of a man's nature and has a power of its own. Isa. $30: 27)^{1}$ ).

As dit so is dan kan die naam in waardevolle aanduiding van die gedagtes van die naamgewers wees. Die Semitiese naamgewing is dan ook die voorwerp van studie gemaak en 'n aantal uitnemende werke het oor die verskillende aspekte van die onderwerp verskyn. Vir die Israelitiese persoonsname kan o.a. die werke van $\mathrm{GRAY}^{2}$ ) en NóTH${ }^{3}$ ) genoem word. Laasgenoemde bewerk die Israelitiese persoonsname in hul verband met die hele Semitiese naamgewing. Vir die Akkadiese kan genoem word die werke van STAMM') en van GEMSER ${ }^{-3}$. Laasgenoemde bewerk die nie-teofore elemente in die Akkadiese teofore persoonsname. Interessante resultate is deur hierdie studies bereik. Natuurlik het alle Semitiese persoonsname nie godsdienstige betekenis nie, maar tog is dit 'n kenmerk wat besonder opvallend is dat so 'n hoë persentasie van die name wel godsdienstige betekenis het. ${ }^{6}$ ) Daar kom nl. groot getalle name voor waarin een of ander aanduiding van 'n godheid as element herkenbaar is, hetsy 'n eienaam hetsy 'n omskrywing van 'n god. Op grond van die gegewens wat hy uit alle Semitiese tale versamel het, kon Noth die geskiedenis van die wyse waarop hierdie sg. teofore persoonsname gegee is, vasstel. Persoonsname kan dien as waardevolle getuienis vir die wêreld- en lewensbeskouing van die naamgewers.

Maar die vraag is of geografiese name nie ook vir ons iets kan sê aangaande die persone wat die name gegee het nie. As 'n mens 'n lys van die geografiese name wat in die Ou Testament voorkom, ondersoek, sal onder hulle 'n hele aantal teofore name aangetref word, hoewel die persentasie hier nie so groot is as by persoonsname nie. En by nader ondersoek blyk dat hierdie name vir ons veel openbaar wat nie op die oppervlakte sigbaar is nie. Die 130 Palestynse teofore geografiese name wat ons in die $\mathrm{Ou}$ Testament aantref, kan van drie aspekte beskou word nl. (1) die teofore elemente, d.w.s. die godename of substitute vir die name, (2) die grammatiese struktuur van die name, (3) die nie-teofore elemente.

1) S. A. Cook, The Old Testament, a Reinterpretation, Cambridge 1936, p. 106.

2) G. B. Gray, Studies in Hebrew Proper Names. London. 1896.

3) MaRTIN Noth, Die Israelitischen Personennamen im Rahmen der gemeinsemitischen Namengebung. Stuttgart. 1928.

t) J. J. Stamim, Die Akkadische Namengebung. Leipzig. 1939.

i) B. Gemser, De Beteekenis der Persoonsnamen voor onze kennis van het leven en denken der oude Babyloniërs en Assyriërs. Wageningen, 1924.

i) Sien verder hieroor: Gemser, BAP, hoofstukke II. III en IV; NotH. DIP, pp. 66-131; GraY, HPN. pp. 277-311. 
I. Wat die teofore elemente betref, blyk dit dat onder 130 name nie minder as 30 verskillende woorde voorkom wat ó eiename van gode of ander omskrywings vir 'n godheid is.) Dit plaas ons midde in 'n politeïstiese wêreld. Sommige van hierdie name kom net eenkeer voor, terwyl El en Baal dikwels aangetref word. Verder kom die teofore elemente oor die hele land voor, hoewel daar tog 'n neiging is dat hulle meer in die suide as die noorde voorkom.

As ons die betekenisse van hierdie teofore elemente ontleed, dan vind ons dat die volgende gedagtes daaraan verbonde is :

(1) gedagtes wat in verband staan met die bodem: (a) gedagtes wat uitdrukking gee aan die heerskappy van die godheid, soos El (maghebber), Baal (besitter, heer), Kades (heilig); (b) gode wat in verband staan met vrugbaarheid soos Baal, Astarte, Kades, Dagon.

(2) Gode wat moontlik in verband staan met die hemelliggame:

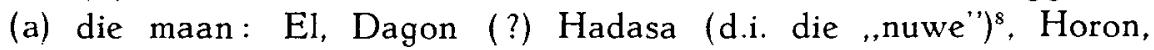
Jerah, Sin, Am, Sur, Terah; (b) die son: Heres, Semes, Baal; (c) die sterre: Gad, Anat, Astarte.

(3) Gode wat in verband staan met die weer: Hadad (donder), Ramman (onweer).

(4) Gode wat in verband staan met die lewe van mense: (a) verwantskap: Am (oom), (b) oorlog: Anat, Salem (c) die eed: Seba, (d) skryfkuns: Nebo, (e) geluk: Gad.

En as hierdie teofore elemente nou in hul verband gesien word met die name soos hulle by ander Semitiese volkere voorkom, dan sien ons dat sommige van die godename soos El en Gad algemeen Semities is. Dan is daar ander soos Aser en Ramman wat meer bepaald as Wes-Semities bestempel kan word. Sommige name kan weer na Babilonië teruggevoer word, bv. Dagon, Lehem, Nebo, Anat, Astarte, Semes, San (?). Ander name weer toon aanrakingspunte met Arabië en veral met Suid -Arabië, bv. Hadasa, Heres, Jerah, Sin, Am, Selem, Sema. Die naam van 'n rivier in Palestina mag die naam van die Egiptiese god Horus bevat maar dit is baie onseker.

Wat egter nog interessanter is as die godename wat voorkom, is diê wat ontbreek. Dit is bv. baie opvallend dat die naam van die God van Israel nl. Jehowa (of Jahwe soos die naam oorspronklik moes gewees het) nie in die geografiese name voorkom nie. Die enigste naam waarin dit moontlik kan voorkom, is die van die berg Moria maar ook dit is baie onseker. ${ }^{10}$ ) Hierdie afwesigheid van die naam

7) nl. El, Aser, Baal, Gad, Dagon, Dan (?), Hadad. Hadasa. Horon, Heres, Jerah, Laban, Lehem, Melek. Nebo, Sin, Am, Anat, Astarte, Sur. Salm, Kades (?), Rimmon, Seba, Salem, Sema, Semes, Sala (San), Terah.

s) Weens moeilikhede om Semitiese lettertekens weer te gee word die name geskryf soos hulle in die Afrikaanse Bybelvertaling voorkom.

9) Die oorspronklike vorm van die naam is Sjagan, en kan verkort word tot Sjan wat in Bet-Sjan voorkom.

10) Selfs die teks is onseker. 
Jahwe tref 'n mens des te meer, aangesien dit baie dikwels in verkorte vorm in persoonsname voorkom soos bv. in die naam Josua en Jesaja. Verder word geografiese name soms gevorm met 'n persoonsnaam as een van die dele daarvan, en dit gebeur dat die naam Jahwe in so 'n persoonsnaam voorkom wat deel van die geografiese naam uitmaak soos bv. in die pleknaam Atrot-Bet-Joab (I Kron. 2.45). Joab is ' $n$ persoonsnaam met die element Jo, wat 'n verkorte vorm van Jahwe is. Maar dit wil voorkom of die Israeliete doelbewus geen geografiese name met die naam van God gevorm het nie. Hoe moet ons die verskynsel verklaar? Dit kan nie verklaar word uit in vrees om die naam van God te gebruik nie, want dan sou die naam Jahwe ook nie in persoonsname voorgekom het nie. 'n Ander moontlikheid mag wees dat die Israeliete nie nuwe plekname gevorm het en daar dus nie verwag kan word om die naam Jahwe aan te tref nie. Hierdie verklaring word egter deur die feite weerspreek. Uit die $\mathrm{Ou}$ Testament blyk dat die Israeliete wel geografiese name gegee het, en uit duidelike tekste soos Num. 32:38 blyk dat hulle ook ou bestaande name deur nuwes vervang het. In 2 Kon. 14:7 word vir ons vertel hoedat koning Amasia die Edomiete verslaan en hul hoofstad Sela (Petra) Jokteël noem. Die naam Jahwe word na die intog ran Israel in Kanaan nie vir 'n geografiese naam gebruik nie. Abraham het geen beswaar gehad om die plek van sy offerande op Moria Jahwe jireh (Gen. 22:14) te noem nie, en ook nie Moses in die geval van die altaar Jahwe nissi nie (Ex. 17:15). Die ongeneentheid om die naam van die God van Israel as 'n element in geografiese name te gebruik, het dus waarskynlik by die intog in Kanaan ontstaan, moontlik omdat die inheemse heidense bevolking die name van hul gode dikwels in plekname gebruik het, en omdat die Israeliete gevrees het dat deur Jahwe te gebruik Jahwe met Baal vereenselwig en dus gelokaliseer kon word. Hierdie gevaar het nie by persoonsname bestaan nie. Daarom kom die naam Jahwe dikwels in persoonsname voor terwyl dit in geografiese name ontbreek.

Ander ontbrekende teofore elemente is die name van Egiptiese gode. Die naam Horus kom miskien in Sihor-Libnat (Jos. 19:26) voor, maar nêrens anders word in Palestynse geografiese naam in Egiptiese god aangetref nie. Dit is heel anders as wat in mens sou verwag, aangesien dit uit die geskiedenis en uit argeologiese opgrawings duidelik is, dat Egipte 'n belangrike politieke rol in Palestina gespeel het. Die verklaring moet of wees dat die name al gevorm was voordat Egipte se invloed in Palestina sterk geword het, of miskien meer waarskynlik, dat die Egiptiese kultuur en godsdiens tog nie so 'n indruk op Palestina gemaak het as die Semitiese nie. Die Semitiese kultuur was sterker as die Egiptiese leërs. Dit is bekend dat Semitiese gode tot in Egipte deurgedring het, en selfs toe laasgenoem- 
de die hele Semitiese wêreld oorheers het, was die amptelike taal van die Faraos vir buitelandse korrespondensie nie die Egiptiese nie maar die Babiloniese taal, soos uit die Amarnatablette blyk. Egiptiese gode het ook wel in Palestina ingang gevind, maar dit het op die geografiese naamgewing so te sê geen invloed gehad nie. BorÉE vermeld in sy werk oor die ou Palestynse plekname") dat meer as een Farao van die Nuwe Ryk Palestynse plekke met Egiptiese name voorsien het. Hierdie name het nie by die inwoners self ontstaan nie, maar is met geweld op hulle afgedwing en het nie by die volk ingang gevind nie. Dit is dus verstaanbaar dat die nuwe name die inheemse nie kon verdring nie, en dat na die vertrek van die vreemde heersers die vreemde name ook verdwyn het. Die enigste Egiptiese naam wat moontlik gebly het, is dié van 'n bron noordwes van Jesusalem ,,die waters van Neftóag" (Jos. 15:9; 18:15) wat soms vertaal word as „Bron van Merneptah."

II. As ons die grammatiese struktuur van die teofore geografiese name ondersoek, dan kan ons drie tipes onderskei: (a) name waarin die godenaam met 'n selfstandige naamwoord verbind word soos Betel (Huis van El), (b) name waarin die godenaam met 'n werkwoord verbind is, bv. Jirpeël (Mag El heel); (c) verkorte name waar een of ander van die elemente weggeval het, bv. Jabne (vgl. Jabneël). By die selfstandige naamwoordverbindinge staan die godenaam na die selfstandige naamwoord wat in die status constructus is, en by die werkwoordverbindinge vind ons die volgorde: werkwoord in die Fiens ${ }^{12}$ ) plus godenaam.

Noтн het in sy werk die grammatiese struktuur van die persoonsname by Israel vergelyk met dié by die res van die Semitiese naamgewing, en tot die gevolgtrekking gekom dat die selfstandige naamwoordverbindinge van hierdie soort die oudste wyse van naamvorming is en buitegewoon dikwels in Noord-Arabies voorkom. Die volgende stadium is dat ' $n$ godenaam en ' $n$ selfstandige naamwoord langs mekaar gevoeg word om 'n nominale sin te vorm. Daarna kom 'n stadium wanneer die godenaam met 'n werkwoord in die Faktum verbind word, en eindelik kom die jongste stadium met die werkwoord in die Fiens, 'n wyse van naamvorming wat in Noord-Arabië onbekend is, hoewel dit in Suid-Arabië voorkom en aan Aramese invloed te danke is. Nou is dit opmerklik dat die twee middelste stadiums by die geografiese name heeltemal ontbreek. Dit sou 'n vingerwysing kon wees dat daar twee duidelik afgeskeie periodes van geografiese naamgewing was en geen geleidelike ontwikkeling nie. In die eerste periode word name soos Berseba (Put van Seba), Jerusalem (eintlik

11) BoRÉE, Die Alten Ortsnamen Palastinäs. Leipzig 1930. Sien p. 113.

12) Die terme Fiens en Faktum word deur GEMSER voorgestel i.p.v. die minder juiste imperfektum en perfektum. Sien GEMSER, Die merkwaardigste verskynsel in die Hebreeuse taal en sy verklaring. Tydskrif vir Wetenskap en Kuns, Band 2. $2 e$ aflewering, 12 Des. 1941. 
Urusalem, d.i. stad van Salem) e.d.m. gevorm. Hierdie tipe van naam gaan ver terug en toon verwantskap met die Noord-Arabiese naamgewing. In die tweede periode is name gegee soos Jisreël (Mag El saai), Jabneël (Mag El bou) e.d.m. en hierdie wyse van naamvorming hang saam met die invloed van die Arameërs wat ook weer na verwant is aan die Arabiere.

Aangesien plekname soos Josefel en Jakobel reeds op die lys van Thutmoses III voorkom, moes die tweede periode al voor $1500 \mathrm{v}$. Chr begin het, want die plekke het die name gedra toe hy hulle verower het. Dit bring albei periodes van naamgewing terug tot die sg. Amoritiese periode in die geskiedenis van Palestina. Dit werp ook weer lig op die gebrek aan spore van Egiptiese invloed, want eers in die sg. Kanaänitiese periode het die invloed in Palestina sterk geword. ${ }^{13}$ )

III. As die name nou van die standpunt van die nie-teofore elemente beskou word, dan kan hieruit ook enige interessante gevolgtrekkinge gemaak word. In die selfstandige naamwoordverbindinge druk die nie-teofore element uit (a) een of ander geografiese eienskap van die plek, soos hoogte, berg, steppe, spruit, rots, fontein; (b) een of ander woonplek of nedersetting of stad; (c) dinge wat in ' $n$ groot nedersetting noodsaaklik is, soos put, pers, toring; (d) die vereringsplek van die godheid nl. "huis". Al hierdie nie-teofore elemente dui die dinge aan wat aan die godheid behoort en waaroor hy heerskappy uitoefen.

By die werkwoordverbindinge kry ons in baie goeie idee van die gedagtes wat die naamgewers aangaande die betrokke gode gehad het $\mathrm{nl}$. die begeertes wat in hul harte geleef het, en dus hul behoeftes, hul houding teenoor die wêreld van mense en dinge, iets van hul lewensomstandighede en die werksaamhede waartoe die gode in staat geag was. Hierdie name is almal in die vorm van wense, en Arabies kom ons hier te hulp om die moontlike betekenis van die werkwoorde vas te stel. So word uitdrukkings gegee aan: (a) wense i.v.m. die godheid self bv. Jehud (Mag hy glansryk wees), Jogbehah (Mag hy hoog wees); (b) wense wat betrekking het op die familiestam of volk wat hom op die plek vestig - hieronder kry ons wense dat die godheid sy welwillendheid mag betoon, dat hy vrygewig mag wees, en sy goed. heid mag bewys, dat hy die volk in staat sal stel om te bou of self sal bou, dat hy die volk sal help, genees, bymekaarhou en dat hy mag verlos (c) wense wat betrekking het op die plek of die bodem-hier word begeertes uitgespreek dat die godheid hom op die plek mag vestig, die woonplek mag aanlê, die land vrugbaar mag maak.

Die beeld wat die name ons aangaande die wense gee is, dat hulle die diep afhanklik gevoel het teenoor die god wat hulle vereer het.

13) Vir die Amoritiese en Kanaänitiese periodes. sien A. Bertholet, Kulturgeschichte Israels, Göttingen 1919, pp. 27 v.v., 53v. 
Hulle het hulp nodig gehad om die woonplek aan te lê en die grond vrugbaar te maak. Hulle het by die god hulp gesoek as die omstandighede ongunstig is en vyande hulle aanval. En as alles goed gaan, dan spreek hulle hul dankbaarheid uit in die wens dat die godheid verheerlik mag word.

Die indruk wat ' $\mathrm{n}$ mens kry, is nie dat dit primitiewe nomadestamme is, wat die name gegee het nie, maar mense wat hulle op die plek gevestig en die grond bewerk het. Hul gedagtes aangaande die gode wat hulle vereer, is gevorderd. Die godheid besit die kenmerke van persoonlikheid, want hy kan gee, help, genees, hy kan sien, die stam bymekaarhou en hulle verlos. Hy besit aan die eenkant glans, majesteit en verhewenheid, maar aan die anderkant woon hy onder sy volk, is hy hulle genadig en vertroos hulle. Die godheid is god van die stam en daar is ' $n$ innige verhouding tussen die stam en sy god. Dit is ook opmerklik dat die groot verskeidenheid godename in die geografiese name van die eerste periode voorkom, terwyl in dié van die tweede periode net El en Am voorkom.

Die studie van hierdie geografiese name het ons dus tot 'n paar definitiewe resultate gebring.

(1) Daar was twee afsonderlike periodes van naamgewing gewees, waarvan die jongste reeds tot voor $1500 \mathrm{v}$. Chr. teruggaan. Die periodes kan nie nader gedateer word nie.

(2) Die name het ons veel gesê i.v.m. die godsdienstige opvattinge van die naamgewers: die soorte gode wat hulle vereer het, en die name van die gode. En deur die soort gode wat hulle vereer het. kan ons ook sien watter soort mense die naamgewers was. En die feit dat die naam van die God van Israel nie voorkom nie, het nuwe lig gewerp op Israel se eerbied vir die Naam.

(3) Aanrakingspunte met verskillende Semitiese volkere is aangetoon. Sommige geleerdes het die neiging gehad om die invloed van een of ander land in die Palestynse kultuur te oordryf om by ' $n$ geliefkoosde teorie in te pas. Die Pan-Babiloniese skool het veel van die Babiloniese invloed gemaak, terwyl die voorstanders van die Jeragmeëliete-teorie weer al die nadruk op die Noord-Arabiese invloed gelê het. Ons studie het ons die beeld van 'n gemengde Semitiese kultuur in Palestina gegee. Van die vroegste tye af was daar tussen die Semitiese volkere 'n wisselwerking met betrekking tot godsdienstige idees, en nie net een volk nie, maar meer as een Semitiese volk het ' $n$ bydrae gelewer.

En in hierdie land met hierdie godsdienstige agtergrond het Israel gekom om die draer te word van die suiwere openbaring. In hierdie 
land is Jesus Christus die Verlosser van die wêreld gebore, en vandaar is die boodskap van vrede met God en die medemense tot aan die uiterste van die aarde gedra. ${ }^{14}$ )

P. F. D. WeIsS. 